\title{
Impact analysis of government investment on water projects in the arid Gansu Province of China
}

\author{
Zhan Wang ${ }^{\mathrm{a}, \mathrm{b}}$, Xiangzheng Deng ${ }^{\mathrm{a}, \mathrm{b}, *}$, Xiubin Li ${ }^{\mathrm{a}}$, Qing Zhou ${ }^{\mathrm{a}, \mathrm{b}, \mathrm{c}}$, Haiming Yan ${ }^{\mathrm{d}}$ \\ a Institute of Geographic Sciences and Natural Resources Research, Chinese Academy of Sciences, Beijing 100101, China \\ ${ }^{\mathrm{b}}$ Center for Chinese Agricultural Policy, Chinese Academy of Sciences, Beijing 100101, China \\ ${ }^{\mathrm{c}}$ University of Chinese Academy of Sciences, Beijing 10049, China \\ ${ }^{\mathrm{d}}$ State Key Laboratory of Water Environment Simulation, School of Environment, Beijing Normal University, Beijing 100875, China
}

\section{A R T I C L E I N F O}

\section{Article history:}

Received 5 October 2014

Accepted 27 March 2015

Available online 13 April 2015

\section{Keywords:}

Water project

CGE

Economic efficiency

Factor mobility

Government investment

Gansu

\begin{abstract}
A B S T R A C T
In this paper, we introduced three-nested Constant Elasticity of Substitution (CES) production function into a static Computable General Equilibrium (CGE) Model. Through four levels of factor productivity, we constructed three nested production function of land use productivity in the conceptual modeling frameworks. The first level of factor productivity is generated by the basic value-added land. On the second level, factor productivity in each sector is generated by human activities that presents human intervention to the first level of factor productivity. On the third level of factor productivity, water allocation reshapes the non-linear structure of transaction among first and second levels. From the perspective of resource utilization, we examined the economic efficiency of water allocation. The scenario-based empirical analysis results show that the three-nested CES production function within CGE model is well-behaved to present the economy system of the case study area. Firstly, water scarcity harmed economic production. Government investment on water projects in Gansu thereby had impacts on economic outcomes. Secondly, huge governmental financing on water projects bring depreciation of present value of social welfare. Moreover, water use for environment adaptation pressures on water supply. The theoretical water price can be sharply increased due to the increasing costs of factor inputs. Thirdly, water use efficiency can be improved by water projects, typically can be benefited from the expansion of watersaving irrigation areas even in those expanding dry area in Gansu. Therefore, increasing governmental financing on water projects can depreciate present value of social welfare but benefit economic efficiency for future generation.
\end{abstract}

(c) 2015 Elsevier Ltd. All rights reserved.

\section{Introduction}

Water and land are scarce natural resource. On the one hand, water supply are mainly influenced by natural environmental changes with the constraint of geographical conditions (Grossmann and Dietrich, 2012). Unique regional climatic adaptation reveals interrelationships between implication of climate changes and potentials of water supply changes (Stroup, 2011). Regional climate changes constantly have impacts on the increase of temperature and the decrease of precipitation, especially on arid land and semi-arid land, study water allocation has to be based on

\footnotetext{
* Corresponding author at: Center for Chinese Agricultural Policy, Chinese Academy of Sciences, Beijing 100101, China. Tel.: +86 106488 8990; fax: +86 10 64856533.

E-mail addresses: lizwang128@gmail.com (Z. Wang), dengxz.ccap@igsnrr.ac.cn (X. Deng), lixb@igsnrr.ac.cn (X. Li), zq_forever@126.com (Q. Zhou), yanhm.
} simlab@gmail.com (H. Yan). a comprehensive model (Lioubimtseva et al., 2005). But under growing human pressure of production and living, quantity of precipitation and runoff on the surface continually are affected by land use and cover changes (Pianosi and Ravazzani, 2010; Singh et al., 2014). Sequentially, in order to preserve water and soil resource for defending severe natural disasters such as floods and droughts (Sivakumar, 2011), large water projects in the hydrological system therefore are invested and built up.

On the other hand, water demand is increasing with climatedriven human intervention. Cultivation and ecological construction aiming to sustainable agriculture have consumed large amount of water resource. It has been proved that interaction among land use and cover changes and climate changes affect crop yields no matter how much technology changes in agricultural facilities (Ciscar et al., 2011; Seto et al., 2000; Veldkamp and Verburg, 2004). Worldwide researchers discussed huge plans of integrated water management from the water supply side to 
enhance water use efficiency. For instance, increase of water storage capacity and decrease of drainage of rainfall for agricultural irrigation, simultaneously, strictly prohibiting exploitation and occupancy of riverbed (Moss, 2004), making innovative water policies at both administrative level and jurisdictional level (Christian-Smith et al., 2011), and so forth. However, water use for environmental adaptation are increasing sharply in arid and semi-arid area, which mainly come from water engineering that exclude natural water supply from precipitation and runoffs. For instance, in urban area, water demands are for building public green, supplementing rivers and artificial lakes; while in rural area, for supplementing swamps and low-lying lakes. Consequently, when facing water demand of expansion of urbanization and cultivated land irrigation, the shrinking water supply has led to severe regional water scarcity (Tekken and Kropp, 2012). Furthermore, population growth is determinate to increase of water demand in all urban-rural regions (Watson and Davies, 2011), and it may have impacts on living standard (Shi et al., 2010).

Public attention then have been drawn on how to value water and how to economically use water. Natural water resource, thereby as externalities of the economic system, has to be marketized with proper economic value (Dudu and Chumi, 2008). Coase (1960) mentioned that markets are considered to be the most efficient way of allocating scarce resources by economic theory even though complete valuation of natural resource is impossible (Coase, 1960; Arrow, 1969). However, impact of water allocation on social welfare has spatial heterogeneity to physical water allocation due to partial economic valuation issues. Partial valuation of natural resource hence leads to Pareto efficiency failed by market failure with asymmetric information. Thereafter, administrative policies always plays uncertain roles to the practical results of welfare allocation mechanism.

Computable General Equilibrium (CGE) modeling from both water supply side and demand side provides insights of policy-oriented impact of water resource allocation (Seung et al., 1997, 1998, 1999; Harris and Mapp, 1986, 1980). It is a systematicequilibrium-based research on water allocation from both water supply side and water demand side, which indicates sustainable adaptation of a regional integrated water system for both ecological and economic development under water scarcity condition (Rosegrant et al., 2000). Based on SAM (Social Accounting Matrix), CGE modeling water allocation will present the allocation of economic value of water consumption. In addition, the distribution of economic value is derived because economic value of resource utilization can be marketized through factor mobility and sectoral interdependence (Griffith, 2012).

Closure condition of factor mobility in CGE modeling presents systematic changes due to the changes of supply and demand of water. Factor mobility among capital, labor, and natural resource which need to be realized and analyzed for efficiently instructing government investment (Tirado et al., 2010). Especially, direct government investment on large water conservancy project has huge impacts on local economic development. For instance, large water transfer project like the Three Gorges Hydraulic Power Station in China cost 5.19 billion in 1993 USD for 1.13 million people migration, and the Hoover Dam in US made great economic contribution of power generation for 8 million people in Arizona, Nevada and California. Furthermore, partial valuation of natural land use results in heterogeneously proportional changes between land price and the price of other normal commodities which is caused by hysteretic price on continual utilization without market transfer (van Heerden et al., 2008). Therefore, modeling water allocation needs to consider more complex structure of the factor inputs from the demand side. It will provide economic insights for policyoriented analysis of the efficiency of government investment on large water projects (Rosegrant et al., 2000). More importantly, macro-view economic valuation of natural water resource through entire engineered economic system can be also assessed by social welfare implication of relative changes through microeconomic approach (Diao et al., 2008).

In the rest of paper, we will introduce the conceptual model design and its specification with introduction of the three-nested CES production function and its relevant semiparametric demand function will be discussed in the Section 2. Thereafter, the information of case study region and the question list will be given before the end of Section 3. In the next following Section 4, we will give the data description and closure condition of each testing model. In this part, specific model description with different conditions of factor mobility are examined. Sequentially, empirical analysis and comparing results based on Scenario I, II, III will be given in the Section 5. This paper ends with a conclusion of research findings and a brief discussion of further research issues.

\section{Methodology}

\subsection{Conceptual model design}

The conceptual model designed three-nested CES production function in the regional CGE model. It means the non-linear relationship among factors are designed instead of traditional linear relationships of CES production function. Intuitively, evolutionary civilization is nonlinear process. It covers endogenous nonlinear technology improvement, nonlinear resource utilization, and nonlinear human activities. Thereafter, researchers have to recognize economic scale are based on different levels of productivity. Therefore, we designed three levels of additional factor input of the nested CES production function in the CGE model as shown in Fig. 1.

Land and capital are designed in the first level of economic scale in this modeling framework. Theoretically, land is irreplaceable resources on the earth. When human being hunt for food in "pristine" environment in ancient time, we have started to learn from natural environment (Jørgensen, 1996). After human learned how to use stone to make fire, our agricultural activities started to rely on how to use land. According to different land utilization, capital has been accumulated through the "learning-by-doing" process to support human sustainable living. With advanced technology, human have constantly created and improved adaptive environment, and built numerous skyscrapers for saving land use, but total available land is still fixed.

Labor as a production factor is designed in the second level of economic scale in this modeling framework. From ancient times to modern times, labor-intensive jobs are gradually substituted by advanced machines. Although endogenous capital growth is attributed to technology improvement, labor contributes to both aspects of capital accumulation and research development. Thus, the substitution of additional labor input is designed at the second level productivity. Human activities brought industrialization and civilization. Our living standard and environment have been improved, but simultaneously polluting the natural environment. Particularly, in recent two hundred years, human-dominated ecosystem (HDE) has been pressured by rapid growth of urbanization expansion (Collins et al., 2000). In the past several decades, "urban fringe" has been paid much attention because ecosystem beside urban area is bearing much pressure of increasing human activities (Müller and Lenz, 2006; Patten, 1995). Moreover, with increasing individual's and public's utility level, government policy becomes easily distorting ecosystem and economic system (Wang et al., 2011). Globally water demand for environmental adaptation and conservation are sharply increasing with downhill climate changes. 


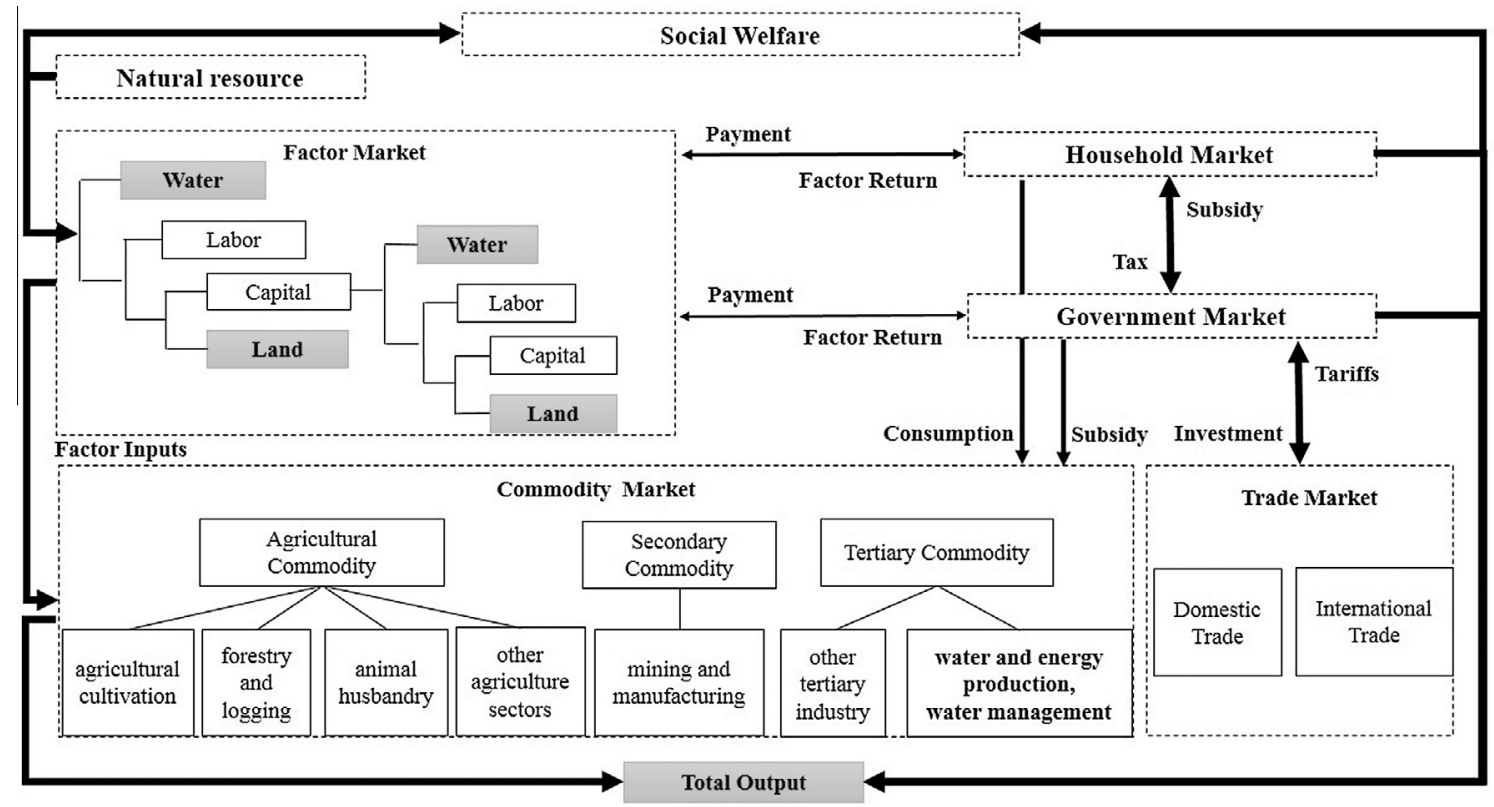

Fig. 1. Integrated modeling structure of supply and demand of water at a regional extent.

Water makes land cover changes through irrigating, impounding, channelling, lifting, transferring, and pumping underground water. However, natural disasters, such as floods and droughts, alternately break down a fragile microclimatic equilibrium. When facing fluctuation of water supply, building water facilities are compelled. Instead, in those area with pleasant weather and rich water, fluctuation of water supply might not influence the economic scale. Therefore, water is designed as production factor directly contributing to total outputs and capital accumulation in this research.

\subsection{Model specification}

\subsubsection{Stone-Geary utility function and consumption theory}

Social welfare utility function is presented by the sum of individual's Stone-Geary utility function in our model. StoneGeary utility function is constructed by every pair of basic elements and independently developed by Nash in 1953 (Neary, 1997). It provides an access to describe the actual cost of living by using a linear expenditure function even though its microeconomic application is based on price theory and usually overestimates the actual rate of inflation. When underlying a hyperbolic form of demand functions derived by the parameters of Cobb-Douglas function, Gorman Polar Form offers a reduced form of the linear expenditure function. It presents the equilibrium between the amount of available income of individual and its possibility frontier of expenditure, which let Stone-Geary utility function be indirect utility function to depict the indifference curve. Thereby, the Roy's Identity will be easily applied for proving the Stone-Geary utility function to get a Marshallian demand function for an individual and a good. Using Roy's Identity through indirect utility function form also can prove the same results in Appendix A. Keynesian saving is directly depending on the rest of aggregated consumption for investment in a "following" economic cycle. Thus, we assume the consumption investment adjusts to let savings drive investment through a demand function which is derived from a Stone-Geary utility function and allowing commodity investment varies with unit price changes. The theoretical deductive reasoning is derived by mathematical approach as follows.

$\min e(p, u)=p_{i} x_{i}^{h}(p, u)+\cdots+p_{j} x_{j}^{h}(p, u)+\ldots$

sj : $U(X)=\prod\left(X_{i}-\mu_{i}\right)^{\beta_{j}}$

$L=\sum_{j} P_{i} X_{i}^{h}-\lambda\left(\prod\left(X_{i}-\mu_{i}\right)^{\beta_{j}}-U\right)$

FOC :

$P_{i}-\lambda \beta_{i}\left(X_{i}-\mu_{i}\right)^{\beta_{j}-1} \prod\left(X_{i}-\mu_{i}\right)^{\beta_{j}}=0$

$\Rightarrow \lambda U=\left(\frac{P_{i}}{\beta_{i}}\right)\left(X_{i}-\mu_{i}\right)$

Soc :

$U=\left(\frac{P_{i}}{\beta_{i}}\right)\left(X_{i}-\mu_{i}\right) \prod\left(\frac{\beta_{j}}{P_{j}}\right)^{\beta_{j}}$

$\because \sum \beta_{j}=1$

$\Rightarrow e(p, u)=\sum_{j} P_{i} x_{i}^{h}=\sum_{j} P_{i} \mu_{i}+U \prod\left(\frac{P_{j}}{\beta_{j}}\right)^{\beta_{j}}$

$\Rightarrow X_{i}=\mu_{i}+\frac{\beta_{j}}{P_{i}}\left(e(p, u)-\sum_{j} P_{j} \mu_{j}\right)$

$x_{i}^{h}=X_{i}=X_{i}^{n}$

\subsubsection{Three nested CES}

Corresponding to our conceptual model, three-level nested Constant Elasticity of Substitution (CES) production functions are designed. McFadden (1963) pointed out no "traditional" definition of large number of factor elasticity of substitution production function (McFadden, 1963). For some complex empirical researches can introduce more factors to depict the empirical evolution. Sequentially, Sato (1967) introduced two-level CES production function to present two levels of economic scale and gave a modified Allen partial elasticity of substitution (Sato, 1967). It allows other factors are partitioned into capital and labor (Shen and Whalley, 2013; Smyth et al., 2011; Su et al., 2012). Koesler and 
Schymura (2012) gave a shot of three level CES nesting structure (Koesler and Schymura, 2012) because "most fittingly term the frequent usage of elasticities of unity the 'idiot's law of elasticities' or the usage of rather arbitrary values as 'coffee table elasticities'." (Dawkins et al., 2001). In order to examine how the interactions and interrelationships among four factors: capital, labor, land, water will affect systematic changes when water demand and supply change, we design three-level nested CES production functions in the following equations.

$$
\begin{aligned}
& X_{i}^{1}=A_{i}^{1}\left(\alpha_{i}^{\kappa} K_{i}^{-\rho_{i}^{\kappa}}+\left(1-\alpha_{i}^{\kappa}\right) N_{i}^{-\rho_{i}^{\kappa}}\right)^{\frac{1}{-\rho_{i}^{\kappa}}} \\
& X_{i}^{2}=A_{i}^{2}\left(\alpha_{i}^{\eta} L_{i}^{-\rho_{i}^{\eta}}+\left(1-\alpha_{i}^{\eta}\right)\left(X_{i}^{1}\right)^{-\rho_{i}^{\eta}}\right)^{\frac{1}{-\rho_{i}^{\eta}}} \\
& X_{i}^{3}=A_{i}^{3}\left(\alpha_{i}^{\omega} W_{i}^{-\rho_{i}^{\omega}}+\left(1-\alpha_{i}^{\omega}\right)\left(X_{i}^{2}\right)^{-\rho_{i}^{\omega}}\right)^{\frac{1}{-\rho_{i}^{\omega}}} \\
& X_{i}^{4}=\frac{A_{i}^{4}}{1-\operatorname{tb}(a)-\sum_{j} i c a(c, a)}\left(\alpha_{i}^{m} M_{i}^{-\rho_{i}^{m}}+\left(1-\alpha_{i}^{m}\right)\left(X_{i}^{3}\right)^{-\rho_{i}^{m}}\right)^{\frac{1}{-\rho_{i}^{m}}}
\end{aligned}
$$

where

$K_{i}$, production factor of capital in sector $i$

$N_{i}$, production factor of land use in sector $i$

$L_{i}$, production factor of labor in sector $i$

$W_{i}$, production factor of water resource consumption in sector $i$

$M_{i}$, intermediate outputs in sector $i$

$\alpha_{i}^{\kappa}$, distribution parameter of capital in sector $i$

$\alpha_{i}^{\eta}$, distribution parameter of labor in sector $i$

$\alpha_{i}^{\omega}$, distribution parameter of water in sector $i$

$\rho_{i}^{\kappa}$, substitution parameter of capital input to land use in sector $i$

$\rho_{i}^{\eta}$, substitution parameter of labor input to total input of capital and land in sector $i$

$\rho_{i}^{\omega}$, substitution parameter of water input to total input of capital, land and labor input in sector $i$

$\rho_{i}^{m}$, substitution parameter of all factor input to intermediate input in sector $i$

$X_{i}^{n}$, outputs in sector $i$ at level of $n, n=1,2,3,4$

$A_{i}^{n}$, efficiency parameter in sector $i$ at level of $n, n=1,2,3,4$

$t b(a)$, indirect business tax of activity $a$,

ica $(c, a)$, Leontief coefficients in production function, quantity of commodity $\mathrm{c}$ as intermediate input per unit of activity a, which is the initial quantity of intermediate use of commodity c by activity a divided by initial activity level.

\subsubsection{Semiparametric factor demand functions in modeling frameworks}

Corresponding to the three-level nested CES production functions, three nested demand function are designed. Nested demand function were presented by multi-level probability based Logit model for bioeconomic study (Carson et al., 2009). Because individuals' willingness-to-pay (WTP) have presented their preference for well-being, and estimates are reported based on improvements in these quantity measures (Egan et al., 2009), the random utility framework based on discrete choice model are becoming increasingly popular in the applied economics literature (Colombo et al., 2009). Theoretically, preference in the set of alternatives are exhaustive, which requires the person choosing one alternative but not choosing any other alternatives at the same time in a finite alternatives set. Semiparametric method provides real expenditure "shape" of the Engel curve which improves parametric method (Pendakur and Sperlich, 2010). Thus, the factor demand equations are derived by value added price of activity $A$ in sector $i$ multiplied by efficiency parameter in sector $i$ and the partial derivatives of the production function with respect to each factor of production.

$$
\begin{aligned}
& W F_{i}^{K}=P V A_{i} * \frac{A_{i}^{1} A_{i}^{2} A_{i}^{3} \alpha_{i}^{\kappa}\left(1-\alpha_{i}^{\eta}\right)\left(1-\alpha_{i}^{\omega}\right)}{1-t b(a)-\sum_{j} i c a(c, a)} K_{i}^{-\rho_{i}^{\kappa}-1} X_{i}^{1^{-\rho_{i}^{\eta}-1}} X_{i}^{2-\rho_{i}^{\omega}-1} \\
& \left(\alpha_{i}^{\omega} W_{i}^{-\rho_{i}^{\omega}}+\left(1-\alpha_{i}^{\omega}\right)\left(X_{i}^{2}\right)^{-\rho_{i}^{\omega}}\right)^{\frac{1}{-\rho_{i}^{\omega}-1}}\left(\alpha_{i}^{\eta} L_{i}^{-\rho_{i}^{\eta}}+\left(1-\alpha_{i}^{\eta}\right)\left(X_{i}^{1}\right)\right)^{\frac{1}{-\rho_{i}^{\eta}-1}} \\
& \left(\alpha_{i}^{\kappa} K_{i}^{-\rho_{i}^{\kappa}}+\left(1-\alpha_{i}^{\kappa}\right) N_{i}^{-\rho_{i}^{\kappa}}\right)^{\frac{1}{-\rho_{i}^{\kappa}}-1} \\
& W F_{i}^{N}=P V A_{i} * \frac{A_{i}^{1} A_{i}^{2} A_{i}^{3}\left(1-\alpha_{i}^{\kappa}\right)\left(1-\alpha_{i}^{\eta}\right)\left(1-\alpha_{i}^{\omega}\right)}{1-t b(a)-\sum_{j} i c a(c, a)} N_{i}^{-\rho_{i}^{\kappa}-1} X_{i}^{1^{-\rho_{i}^{\eta}-1}} X_{i}^{2^{-\rho_{i}^{\omega}-1}} \\
& \left(\alpha_{i}^{\omega} W_{i}^{-\rho_{i}^{\omega}}+\left(1-\alpha_{i}^{\omega}\right)\left(X_{i}^{2}\right)^{-\rho_{i}^{\omega}}\right)^{\frac{1}{-\rho_{i}^{\omega}-1}}\left(\alpha_{i}^{\eta} L_{i}^{-\rho_{i}^{\eta}}+\left(1-\alpha_{i}^{\eta}\right)\left(X_{i}^{1}\right)\right)^{\frac{1}{-\rho_{i}^{\eta}-1}} \\
& \left(\alpha_{i}^{\kappa} K_{i}^{-\rho_{i}^{\kappa}}+\left(1-\alpha_{i}^{\kappa}\right) N_{i}^{-\rho_{i}^{\kappa}}\right)^{\frac{1}{-\rho_{i}^{\kappa}}-1}
\end{aligned}
$$$$
W F_{i}^{L}=P V A_{i} * \frac{A_{i}^{2} A_{i}^{3} \alpha_{i}^{\eta}\left(1-\alpha_{i}^{\omega}\right)}{1-t b(a)-\sum_{j} i c a(c, a)} L_{i}^{-\rho_{i}^{\eta}-1} X_{i}^{2^{-\rho_{i}^{\omega}-1}}
$$$$
\left(\alpha_{i}^{\omega} W_{i}^{-\rho_{i}^{\omega}}+\left(1-\alpha_{i}^{\omega}\right)\left(X_{i}^{2}\right)^{-\rho_{i}^{\omega}}\right)^{\frac{1}{-\rho_{i}^{\omega}}-1}\left(\alpha_{i}^{\eta} L_{i}^{-\rho_{i}^{\eta}}+\left(1-\alpha_{i}^{\eta}\right)\left(X_{i}^{1}\right)\right)^{\frac{1}{-\rho_{i}^{\eta}}-1}
$$$$
W F_{i}^{W}=P V A_{i} * \frac{A_{i}^{3} \alpha_{i}^{\omega}}{1-t b(a)-\sum_{j} i c a(c, a)} W_{i}^{-\rho_{i}^{\omega}-1}
$$$$
\left(\alpha_{i}^{\omega} W_{i}^{-\rho_{i}^{\omega}}+\left(1-\alpha_{i}^{\omega}\right)\left(X_{i}^{2}\right)^{-\rho_{i}^{\omega}}\right)^{\frac{1}{-\rho_{i}^{\omega \omega}}-1}
$$

where

$P V A_{i}$, value added price

$W F_{i}^{K, N, L, W}$, demand of production factors of capital $(K)$, land $(N)$, labor $(L)$, water $(W)$ in sector $i$.

\subsubsection{Mixed Complementarity Problem (MCP)}

Technically and theoretically, maximum social welfare in an linear objective function with a group of constraints including linear constraints and nonlinear constraints constitute a MCP. It has been proven that the Nash Equilibrium point is equivalent to Linear Complementarity Problem (LCP) based on bimatrix games (Lemke and Howson, 1964). When Karush-Kuhn-Tucker (KKT) conditions as the first order condition are set as the constraint of quadratic programming, the Mixed Complementarity Problem (MCP) is constituted based on the LCP. Quantity of supply and demand thereby can be considered as bimatrix games from two convex sets by linking with variational inequalities in Euclidean space. Because elastostatics problem in linear elasticity attributes to variational inequality, study on the elastic equilibrium configuration of an anisotropic non-homogeneous elastic body is the problem with ambiguous boundary conditions. It could also be reinterpreted as the problem of how to linearize the non-linear theory of elasticity within the finite strain theory, so that lagrangian description and Eulerian description are usually introduced to solve partial differential equations for regularity of non-linear deformation. Therefore, the SOLVER of PATH was used for solving MCP in GAMS (The General Algebraic Modeling System), and the main function in our CGE model are in the following sections. 


\section{Case study area of Gansu Province}

\subsection{General information}

Gansu Province, including fourteen prefectures, is located at northwest of China. It has a population of 26 million in 2008, on the total area of $425,800 \mathrm{~km}^{2}$ mostly covered by semi-arid to arid land, alternatively influenced by subtropical monsoon climate and temperate continental climate. From 1950 to 2008, the average of annual temperature is between 9 and $10^{\circ} \mathrm{C}$; the average of annual precipitation is about $276.9 \mathrm{~mm}$. Its total amount of available annual water resources is around 24.4 billion $\mathrm{m}^{3}$ in 2008, but available water were less than $1100 \mathrm{~m}^{3}$ per capita, which is only a half of the national average or one-eighth of the world's average.

Gansu were undergoing a rapid transformation of industrialization with flourishing in Tertiary Industry from 1980s. The Secondary Industry was about 45\% of total GDP and had an increasing trend. The Tertiary Industry was about $40 \%$ of total GDP, and the conventional Primary Industry had decreased to just $15 \%$ share of the total GDP from 2002 to 2008 . However, water demand of industrial activities and residential living were slightly decreased from 2002 to 2008 in Fig. 2, but population increased from 26.03 to 26.35 million, about $1.22 \%$ of population in 2002 .

Moreover, industrialization is slower than urbanization in Gansu by comparing $45 \%$ of the proportion of Secondary Industry in GDP to the $38.75 \%$ in urbanization cover rate. The lag of civil infrastructure and urban construction is hard to absorb migration into urban area. Thereafter, lacks of industrial consumption through marketized mechanism easily slower the speed of industrialization due to lacks of labor, and then, industrialization expansion becomes hard to be supported. In Gansu Province, around 26.5 million people are living on 0.045 million $\mathrm{km}^{2}$ cultivated land. About $28 \%$ of cultivated land were needed to be irrigated until 2008 which consumed $75 \%$ of total water use per year. According to the Provincial Government Work Report in 2013, the urbanization cover rate was about $38.75 \%$ of total area in Gansu Province until the end of 2012, which was lower than the national average at $52.57 \%$, ranking the fourth nationwide from bottom. From 2002 to 2008, total ecological water use was from 214 million $\mathrm{m}^{3}$ increased to 299 million $\mathrm{m}^{3}$ (Water Resources of the People's Republic of China, 2003-2009). Thus, increasing water demand of environmental adaptation for urbanization gradually draw public attention.

Water scarcity is still severe due to the constraints of regional characteristics of the unique geographical location. Lanzhou, the largest urban area in Gansu Province, was the latest focus posted on newspapers and TV channels in China because there citizens were suffering severe water scarcity, Shui Huang in Chinese, that was threatening to water use for daily living. Water resource stock per capita in Lanzhou decreased to $720 \mathrm{~m}^{3}$, about $22 \mathrm{~m}^{3}$ lower in 2012, which was even much lower than the international average security level at $1000 \mathrm{~m}^{3}$. Some other rural area of Gansu Province were also suffering severe water scarcity with heavy poverty, such as Huanxian County, Huining County, and Jingyuan County. These three counties are about total $9236 \mathrm{~km}^{2}$ with lack of $119 \mathrm{~m}^{3}$ of water resource stock per capita, and farmer's income per capita was about 162 in 2005 USD.

Additionally, drought area were expanding from 2002 to 2008. By analyzing the distribution of precipitation from 2002 to 2008, and comparing them to the historical annually average precipitation to get the percentage of precipitation anomalies in 2002 and 2008, two figures were generated for presenting spatial distribution of drought area in Gansu Province. The left picture in Fig. 3 presents the spatial distribution of drought area in Gansu Province in 2002, and the right picture in Fig. 3 presents the spatial distribution of drought area in Gansu Province in 2008. The color from light to dark in the figures presents the extent of drought from No drought, Slight drought, Moderate drought, Heavy drought, to the Extreme drought. The interpretation and calculation steps were followed in Appendix B Table 10. The geographical analysis shows the drought area were expanded by $12.26 \%$ of the total area in 2002 until 2008.

However, according to Gansu water resource 2002-2008, total water supply fluctuated from the average level between -151 and 123 million $\mathrm{m}^{3}$ (Fig. 4a). Total water demand in Gansu attributed to agricultural irrigation, industrial activities, municipal and residential living, was fluctuated from the average level between -285 and 142 million $\mathrm{m}^{3}$ from 2002 to 2008 (Fig. 4b). Changes of total water demand from three watersheds was $-327 \sim 342$ million $\mathrm{m}^{3}$ (Fig. 4c). Water scarcity had been wavingly mitigated from 1366 million $\mathrm{m}^{3}$ in 2002 to 1140 million $\mathrm{m}^{3}$ in 2008 because actual water use was slightly decreasing in Gansu Province (Fig. 4d).

Therefore, under the backgrounds of urbanization and drought area expansion in Gansu Province, many questions have not been answered yet. For instance, how many percentage changes of economic production is driven by changes of water scarcity? What does its economic impact have effects on economic structural changes? How much rural and urban welfare will be reallocated? While how government investment influence to this process, what did economic outputs were changed by large water projects? This study on both sides of water supply and water demand through our modeling works will give the insightful clues to answer these questions.

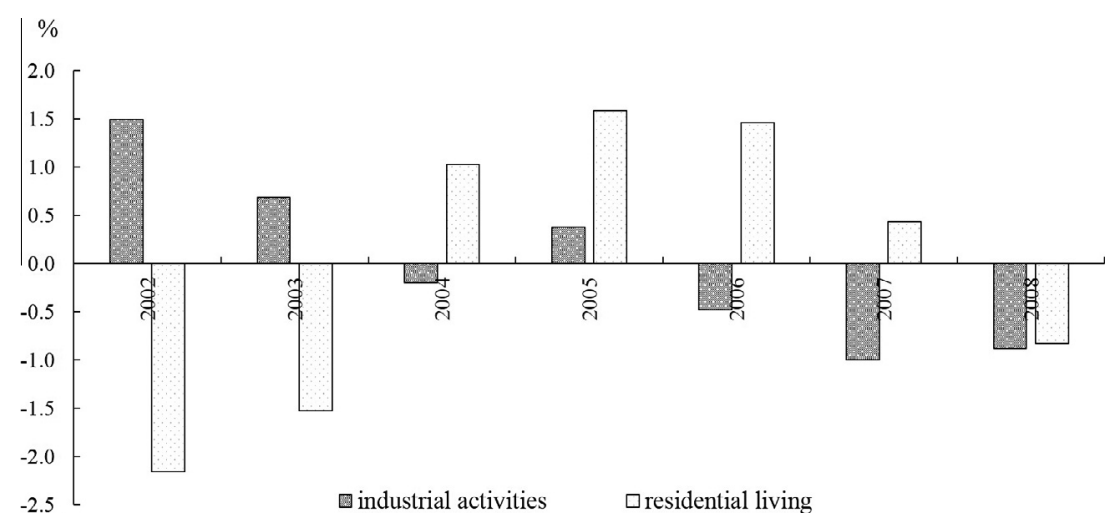

Fig. 2. Changes of water demand of industrial activities vs residential living in Gansu 2002-2008. 

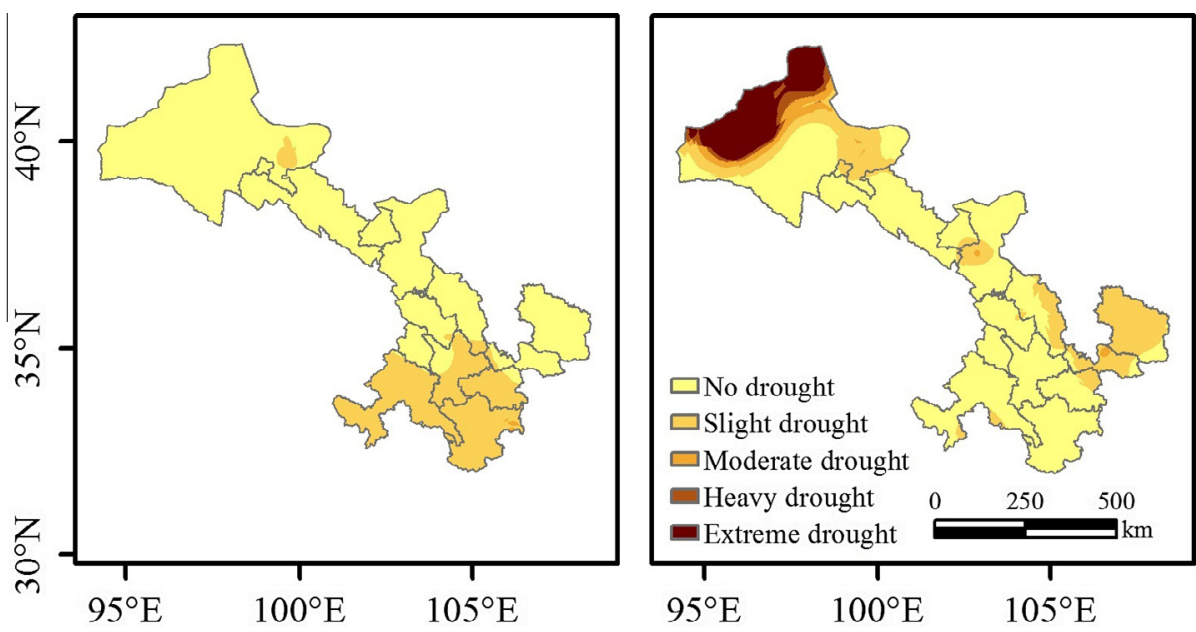

Fig. 3. Changes of spatial distribution of drought area in Gansu province 2002 vs 2008.
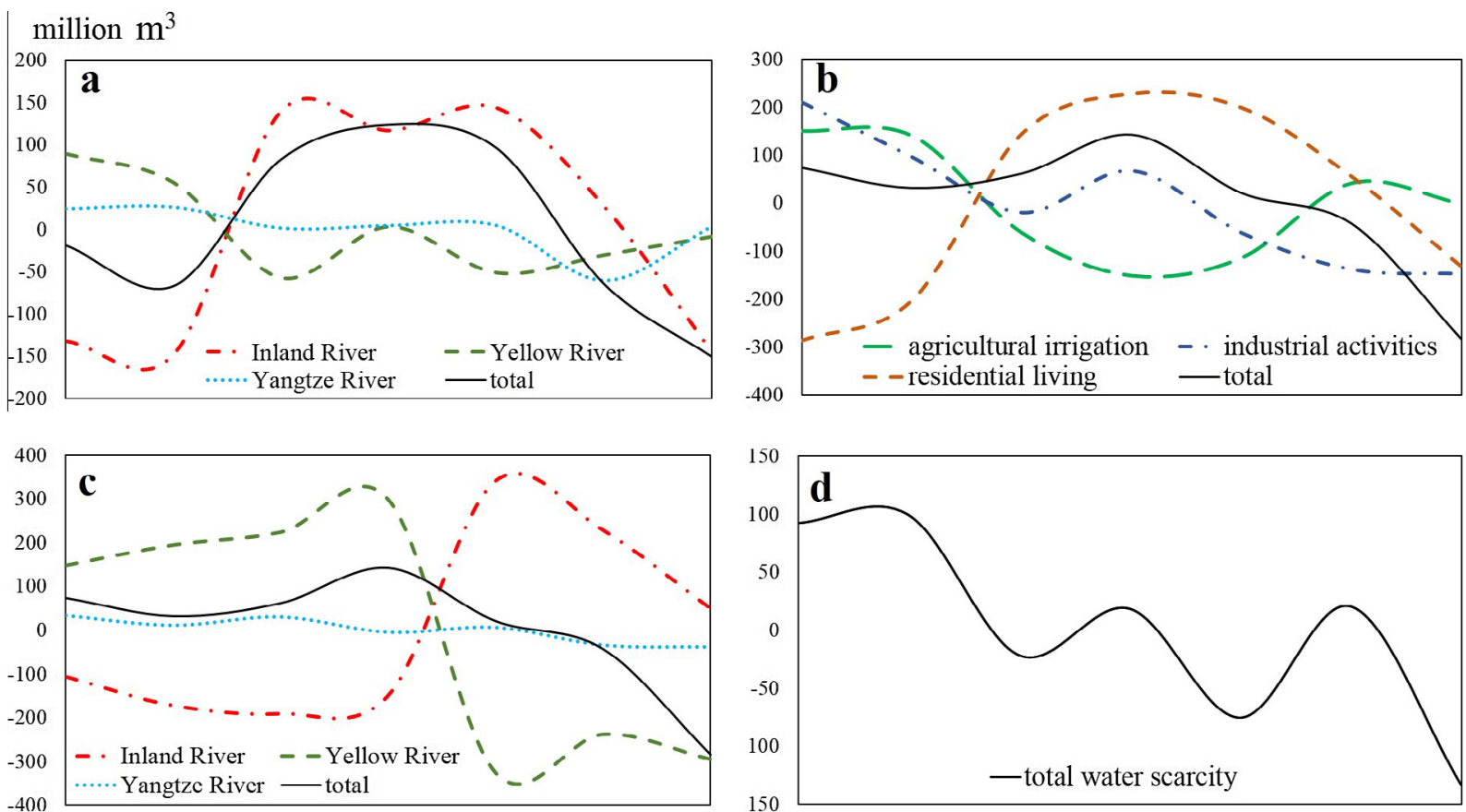

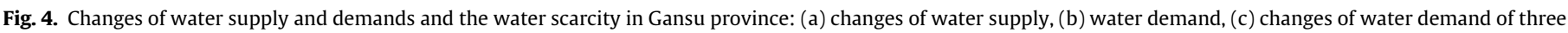
watershed and (d) total water scarcity in Gansu province from 2002 to 2008.

\section{Data description and closure condition}

\subsection{Data description}

Water in Gansu are supplied by the Yellow River, Yangtze River, and all inland rivers. According to Gansu water resource 2007, published by Gansu Provincial Water Resource Bureau, water supply in Gansu comes from the Yellow River, Yangtze River, and all inland rivers, by six types of water supply including water storage, diversion, lift, transfer, pumping underground water, and other retreatment in Table 1.

According to Gansu water resource 2007, published by Gansu Provincial Water Resource Bureau, water demand in Gansu are going through eight aggregated sectors in Table 2: FARM (agricultural cultivation), FOST (forestry and logging), DAR (animal husbandry), OAGR (other agriculture sectors), MAN (mining and manufacturing), WSP (water and energy production, water management), TER (tertiary industry for urbanization: building,

Table 1

2007 Water supply in Gansu province.

\begin{tabular}{llccc}
\hline Supply types & $\begin{array}{l}\text { All inland } \\
\text { rivers (million } \\
\left.\mathrm{m}^{3}\right)\end{array}$ & $\begin{array}{l}\text { Yellow river } \\
\left(\text { million } \mathrm{m}^{3}\right)\end{array}$ & $\begin{array}{l}\text { Yangtze river } \\
\left(\text { million } \mathrm{m}^{3}\right)\end{array}$ & $\begin{array}{l}\text { Total } \\
(\mathrm{million} \\
\left.\mathrm{m}^{3}\right)\end{array}$ \\
\hline Impounding & 3191 & 221 & 19 & 3431 \\
Channelling & 2256 & 1796 & 93 & 4145 \\
Lifting & 6 & 1610 & 70 & 1686 \\
Transferring & 64 & 0 & 0 & 64 \\
Underground & 2066 & 65 & 71 & 2787 \\
$\quad$ water & 75 & 61 & 61 & 197 \\
Other & 7657 & 4338 & 315 & 12,310 \\
Total & & & &
\end{tabular}


Table 2

2007 Water use and land use in Gansu province.

\begin{tabular}{|c|c|c|c|}
\hline $\begin{array}{l}\text { Code in } \\
\text { GAMS }\end{array}$ & Sector description & $\begin{array}{l}\text { Water use } \\
\left(\text { million } \mathrm{m}^{3}\right)\end{array}$ & $\begin{array}{l}\text { Land use } \\
\left(\mathrm{km}^{2}\right)\end{array}$ \\
\hline FARM & Agricultural cultivation & 9312 & 46,237 \\
\hline FOST & Forestry and logging & 406 & 53,892 \\
\hline DAR & Animal husbandry & 135 & 141,069 \\
\hline OAGR & Other agriculture & 13 & 12,967 \\
\hline MAN & Mining and manufacturing & 1178 & 9767 \\
\hline WSP & $\begin{array}{l}\text { Water supply and } \\
\text { production sector }\end{array}$ & 136 & 288 \\
\hline TER & $\begin{array}{l}\text { The Tertiary Industry for } \\
\text { urbanization }\end{array}$ & 490 & 403.9 \\
\hline OTER & Other tertiary industry & 642 & 445.3 \\
\hline $\begin{array}{l}\text { Total in } \\
\text { Gansu }\end{array}$ & & 12,312 & $265,069.2$ \\
\hline
\end{tabular}

transportation and post service, communication, wholesale and retail), OTER (other tertiary industry). Cross-sectional data of water use and land use were published in Gansu water resource 2007.

Based on Gannsu input-output table 2007, published by Statistics Bureau of Gansu Province, a Social Accounting Matrix (SAM) was constructed. The average water price published by the Price Bureau of Gansu Province were used for calculating initialized economic valuation of water use in each aggregated sector. See the mathematical formulae as follows (Deng et al., 2014).

For water consumption in agricultural sector

$W I_{\text {crop }}=\frac{G O_{\text {irrigated }}-G O_{\text {non-irrigated }}}{W A_{\text {irrigated }}-W A_{\text {non-irrigated }}} \times W A$

For water usage in other industries $i$

$W I_{i}=G O_{i} \times C_{i} \times P_{i}$

Deng $(2012,2014)$ discussed initialization of land use were in CGE modeling (Deng et al., 2010, 2012). In this research, the initialized economic valuation of land use in each sector was from the proportional Land Tax published in Gansu finance yearbook 2008. Transfer Payment Matrixes between Household and Government were proportionally assessed according to Gansu cash flow statement 2007 published by Statistics Bureau of Gansu Province. Transpose Matrixes were calculated from China's economic and social development statistical database: Gansu development yearbook 2007 published by China Statistics Press. Because these data were estimated by the proportions according to fragmental financial reports, governmental financing on water projects as a lump sum amount was plugged into SAM to be a unique sector

Table 3

Closure condition of factor mobility in four testing CGE modeling government investment on Gansu's water projects in 2007.

\begin{tabular}{|c|c|c|c|c|c|}
\hline & & $\begin{array}{l}\text { Model } \\
\text { I }\end{array}$ & $\begin{array}{l}\text { Model } \\
\text { II }\end{array}$ & $\begin{array}{l}\text { Model } \\
\text { III }\end{array}$ & $\begin{array}{l}\text { Model } \\
\text { IV }\end{array}$ \\
\hline WATER & Mobile & $\sqrt{ }$ & $\sqrt{ }$ & $\sqrt{ }$ & $\sqrt{ }$ \\
\hline LAND & $\begin{array}{l}\text { Mobile } \\
\text { Fixed } \\
\text { Partially fixed }\end{array}$ & $\sqrt{ }$ & $\sqrt{ }$ & $\sqrt{ }$ & $\sqrt{ }$ \\
\hline CAP & $\begin{array}{l}\text { Mobile } \\
\text { Fixed } \\
\text { Partially fixed }\end{array}$ & $\sqrt{ }$ & $\sqrt{ }$ & $\sqrt{ }$ & $\sqrt{ }$ \\
\hline LABOR & $\begin{array}{l}\text { Mobile } \\
\text { Fixed }\end{array}$ & $\sqrt{ }$ & $\sqrt{ }$ & $\sqrt{ }$ & $\sqrt{ }$ \\
\hline SAVING & $\begin{array}{l}\text { CPI changes } \\
\text { Demand derived(savings } \\
\text { drives investment) }\end{array}$ & $\sqrt{ }$ & $\sqrt{ }$ & $\sqrt{ }$ & $\sqrt{ }$ \\
\hline
\end{tabular}

GOVENT in GAMS. Other data of urban and rural population, labor income per capita, and provincial government expenditure were published by Statistics Bureau of Gansu Province.

\subsection{Factor mobility and closure condition for each testing model}

For empirical analysis, four models are designed according to different settings of factor mobility in Table 3. Factors are invested to productive activities usually including capital and labor. Additionally, natural resources as factor inputs were presented for better understanding interrelationships between human activities and environmental adaptation. Thereby, land and water hence are discussed to study economic production at various levels when minimizing the cost per unit of factor inputs. Every unit of additional factor inputs has proportional impacts on economic scale when allowing free trade. Free trade among sectors or countries depends upon sectoral interdependence across industries and borders. Thereafter, factor mobility is ability to move factor from a sectoral production process to another sectoral production process under the assumption of laisser faire.

Because factor mobility is assumed as the first rationale to study on market efficiency, per unit of exchanges cost in the free market is considered as the closest assumption to reality. For example, if a manufacture factory fires people who thereafter get jobs as waiters or waitresses in restaurants, we assumed that is labor mobility; and when the factory sells its assets to a mining or chemical plant, which is considered as capital mobility; additionally, if the new buyer takes the charge of the old factory and pays for the water use bill, it is assumed as water mobility; if the new buyer sells the rights of utilization of land property, it is considered as land use mobility. Partially fixed factor supply is also set up when factor supply to certain sectors is fixed, but to other sectors is mobile. Thus, four models were set for this study.

\section{Results and analysis}

In this study, mitigation of water scarcity was seemingly caused by decreased water demand. However, water scarcity ultimately is caused by the annual increase of human demand for economic growth and the possibly annual decrease of natural supply (Blignaut and Van Heerden, 2009). Because it is ambiguous relationships between water scarcity and the relative changes of water supply and demands, we need to figure out whether government investment on water projects is good or bad. Therefore, with the pressure of decreasing water supply and increasing demand for urbanization and environmental adaptation, three scenarios are sequentially designed in the following Table 4.

\subsection{Scenario $I$}

According to the above geographical analysis of drought expansion, more area were getting dryer because of decreasing precipitation. In addition, total water supply had already decreased

Table 4

Scenario conditions for testing CGE modeling government investment on Gansu's water projects in 2007.

\begin{tabular}{ll}
\hline Scenario & Condition \\
\hline I & $\begin{array}{l}\text { Natural water supply decrease } 5 \% \text { according to drought area } \\
\text { expansion in Gansu } \\
\text { II }\end{array}$ \\
& $\begin{array}{l}\text { Natural water supply decrease } 5 \% \text {, and economic outputs increase } \\
10 \% \text { for urbanization }\end{array}$ \\
III & $\begin{array}{l}\text { Natural water supply decrease } 5 \% \text {, and economic outputs increase } \\
10 \% \text { for urbanization, with government investment of water- } \\
\text { saving for increasing water supply } 1 \%\end{array}$ \\
&
\end{tabular}


Table 5

Changes of economic production in Gansu by four testing models under Scenario I value of output (sales).

\begin{tabular}{lrrrr}
\hline $\begin{array}{l}\text { Value of output (sales) } \\
\text { percentage changes (\%) }\end{array}$ & Model I & Model II & Model III & \multicolumn{1}{l}{$\begin{array}{l}\text { Model } \\
\text { IV }\end{array}$} \\
\hline FARM & -75.71 & -1414.58 & -820.99 & -186.87 \\
FOST & -92.72 & -42988.14 & 233840.70 & -131.46 \\
DAR & -79.52 & -14058.76 & -6636.64 & -97.34 \\
OAGR & -3.56 & -294.36 & 121.84 & -10.68 \\
MAN & -85.56 & -4.76 & 262.98 & -13.39 \\
WSP & -125.99 & -0.20 & 203.55 & 0.84 \\
TER & -79.18 & -0.15 & 102.39 & 0.27 \\
OTER & -50.50 & -0.10 & 101.80 & 0.41 \\
GOVENT & -100.00 & -0.14 & 102.35 & 0.28 \\
\hline
\end{tabular}

from 12.20 billion $\mathrm{m}^{3}$ to 12.06 billion $\mathrm{m}^{3}$ from 2002 to 2008 , which accounts for $1.08 \%$ of the total water supply in 2002 . Thus, if taking $5 \%$ off the total water supply in the future next five years, all agricultural sectors will be harmed by water shortage which are indicated by empirical results from four models in Table 5 . There is except FOST (forestry) and OAGR (other agricultural service) in Model III due to setting land factor as partial mobility. From 1999, Gansu was set as one of the most important provinces to implement the project of returning farmland to forests or grassland. Until the end of 2007, there were about total $17454.2 \mathrm{~km}^{2}$ of cultivated land converted to forest or grassland. China central government subsidized over 0.4 billion in 2008 USD to the provincial government of Gansu Province for supporting over 7. 29 million people including 1.67 million famers involved into this huge project, as well as consolidating vegetation growth. According to the specification for assessment of forest ecosystem services in China (LY/T 1721-2008) regulated by the State Forestry Administration, P.R. China, Wang et al. (2012) gave the estimated total value of forest ecosystem services in Gansu Province. The total economic value was 31.13 billion in 2008 USD; including 12.29 billion of services values of water storage, 5.45 billion of soil conservation, 7.62 billion of Carbon fixation and Oxygen release, 0.68 billion of nutrients accumulation, 1.72 billion of environment purification, 3.1 billion of biodiversity conservation, and 0.25 billion and 0.03 billion in 2008 USD of forest conservation and recreation respectively (Wang et al., 2012). From 2002 to 2008, Gansu water scarcity was decreasing but water use for urbanization and environmental adaptation was oppositely increasing which is shown by Fig. 5. Thus, it indicated the forest sector might still gain a lot when setting land partial mobility and allowing other factors mobile in Gansu. Because government investment is forcing ecological construction to support environmental adaptation, the Secondary and Tertiary Industries will gain very little, but agricultural sectors will be inevitably harmed when facing a water storage.

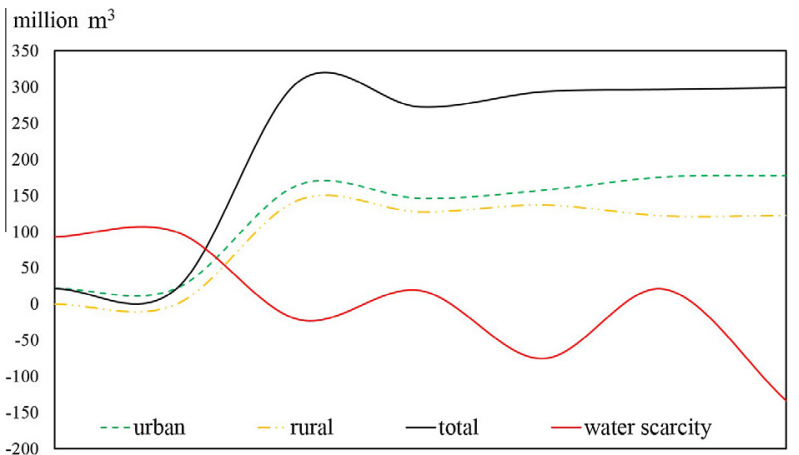

Fig. 5. Gansu water use for environmental adaptation vs water scarcity 2002-2008.
By comparing results among four models in Scenario I, when only allowing water mobile and other factors fixed in Model I, the economic structure of Gansu Province was modified by governmental financing (GOVENT) under the assumption of CPI changes with respect to unit price changes. In Model II, when setting water mobile and capital partially mobile and other factors fixed, all sector outputs have losses due to water shortage. It indicated the economy was harmed by limitation of the mobility of land and labor. Thereby, in Model III, when setting water, labor and capital are mobile, and land is partially mobile under the assumption of demand function derived "saving drives investment" in a short run, the nonlinear relationship among factors through three level CES production function presents that the economic scales can be easily reshaped by governmental expenditure preference of water projects in this case study. Thus, Model IV was designed for testing how "free-will" factor mobility contributes to the changes of Gansu economic structure when facing water shortage. From the results of Scenario I in Model IV, water production sector gains the most. When facing water shortage, unit price of water is increased which absorbs other factor inputs for producing more water. Hence land property with water right will be pursued through marketized mechanism. Capital investment will seek higher benefit-return from water production, and labor will seek higher-wage job if their capabilities could position cross-industry tasks in the sector of water production.

\subsection{Scenario II}

The actual growth rate of GDP in Gansu from 2008 to 2013 was about $10-12.5 \%$. In the past several years the growth rate of urbanization in Gansu was about 10\% according to Provincial Government of Gansu Province's work report of 2013. Thus, in Scenario II, if water supply decrease $5 \%$, and urbanization demand for outputs increase $10 \%$ based on 2007 dataset, the empirical results show that the actual economic value of urbanization (Tertiary Industry outputs for urbanization) was depreciated a lot if all factors are allowed to be mobile under the unit price assumption in Table 6.

Governmental subsidy also was depreciated because of the high social cost of water production which shock the engineered monetary system under the Scenario II. Moreover, Fig. 6a shows that water use for industrial and agricultural activities of urbanization expansion was fluctuated decreasing from 2002 to 2008. It led to the total water use for urbanization expansion therefore decreased from 1.89 billion $\mathrm{m}^{3}$ in 2002 to 1.28 billion $\mathrm{m}^{3}$ in 2008 . However, Fig. 6b shows that Gansu water use for municipal construction, environment, and public service had totally increased $38.46 \%$ of that water use in 2002. Under the Scenario II, if calculating the unit price of WSP in Model IV in Table 5, water unit price was increased by 0.077 USD per $\mathrm{m}^{3}$ (773 USD per ten thousand tons) in 2008 USD. It illustrates water becomes much scarcer. Comparing the

Table 6

Comparative results of sectoral activities price in Gansu by four testing models under Scenario I vs II.

\begin{tabular}{lrrrr}
\hline $\begin{array}{l}\text { Activity price (unit } \\
\text { price) }\end{array}$ & Model I & Model II & \multicolumn{1}{l}{ Model III } & Model IV \\
\hline FARM & -0.55 & 0.41 & 962.42 & 1.37 \\
FOST & -1.04 & 0.19 & 218.84 & -2.39 \\
DAR & 83.69 & -0.06 & 7.43 & -35.36 \\
OAGR & 0.39 & 0.00 & 1.81 & -2.09 \\
MAN & -7.32 & 0.53 & 41.06 & 2.78 \\
WSP & -410.88 & -100.83 & -116143.13 & 5369.86 \\
TER & 1195.68 & -155.40 & -14374.25 & -14864.67 \\
OTER & -360.85 & 175.12 & 40228.49 & 13306.90 \\
GOVENT & 1116.17 & -1003.00 & -905.65 & -1913.73 \\
\hline
\end{tabular}


million $\mathrm{m}^{3}$

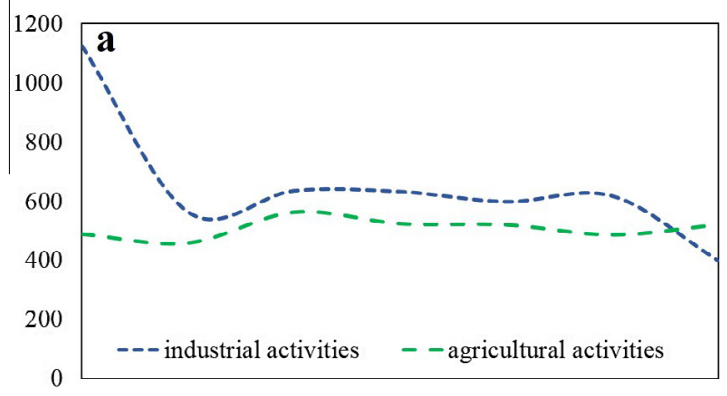

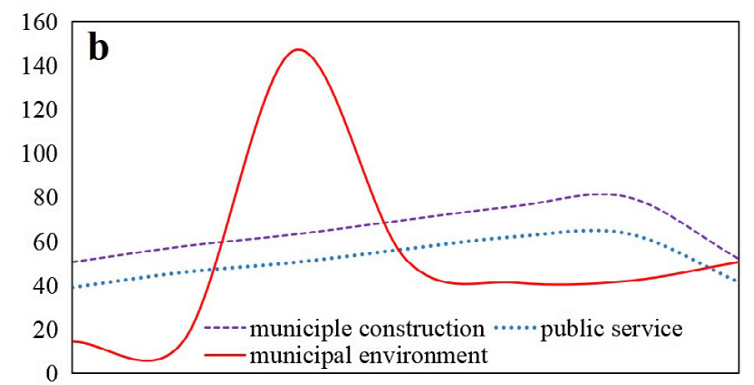

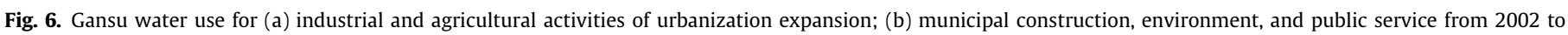
2008.

Table 7

Changes of household utility in Gansu by four testing models under Scenario II.

\begin{tabular}{lcccc}
\hline Household utility (\%) & Model I & Model II & Model III & Model IV \\
\hline Rural & 4.34 & -4.11 & -6.48 & -6.42 \\
Urban & -0.09 & -5.93 & -35.19 & -6.05 \\
\hline
\end{tabular}

empirical results between Model I-III and Model IV, land mobility is the critical setting which detects marketized mechanism with governmental financing. In Model IV, if taking land mobile, potential exchange unit price of farming yield was increased 0.197 in 2008 USD per unit of output, while the real economic value of livestock husbandry was decreased by 5.091 in 2008 USD per unit of output. Intuitively, when facing water scarcity, human will contend for more water with other animals, thereafter the livestock industry was shrinking in Table 5 due to high cost of water to feed animals with the fixed amount of inputs in a short run in Table 6. Manufacturing and mining gained a little for increasing demand of water retreatment.

In addition, empirical analysis shows that individual utility lost under Scenario II. Gansu's rural and urban population respectively was 17.83 and 8.45 million in 2007. Rural Household Utility lost in Model II-IV under the Scenario II in Table 7. Consequently, if factor mobility theoretically represents the perfectly-competitive market efficiency with zero transaction cost, social welfare would lose when facing water scarcity no matter how water demand changes. Comparing Household Utility between rural residents and urban residents, the later would lose no matter how market efficiency changes when facing water scarcity with urbanization expansion. Although the Net Household Income would be increased in Model I-III under the unit price assumption, when allowing land mobile, both rural and urban residents would lose, and their utility would be decreased under the constraint of water scarcity in Table 8 .

\subsection{Scenario III}

The implication of large government investment might not be so positive, even though Provincial government of Gansu Province had invested and subsidized over 0.51 billion in 2005 USD to large water projects from 2002 to 2008. According to Provincial Government of Gansu Province's work report of 2008,

Table 8

Changes of net household income in Gansu by four testing models under Scenario II.

\begin{tabular}{lrlll}
\hline Net household income (\%) & Model I & Model II & Model III & Model IV \\
\hline Rural & 117.53 & 0.00 & 0.05 & -0.03 \\
Urban & 30.81 & 3.16 & 0.06 & -0.31 \\
\hline
\end{tabular}

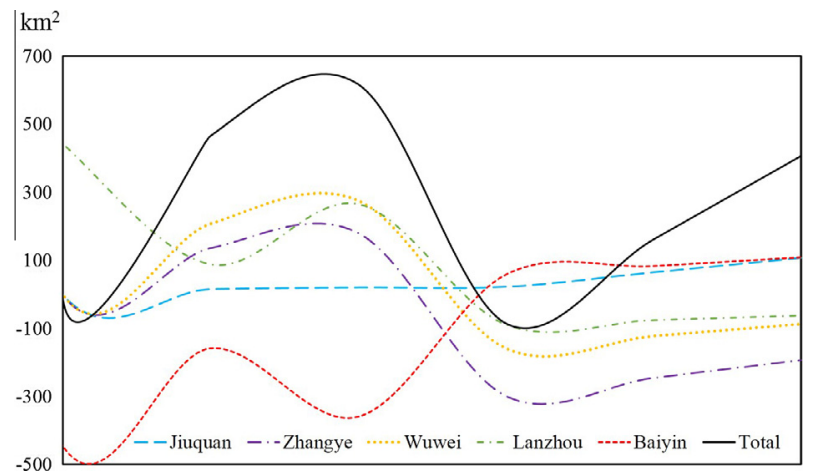

Fig. 7. Gansu water-saving irrigation area changes in mainly administrative regions 2002-2008.

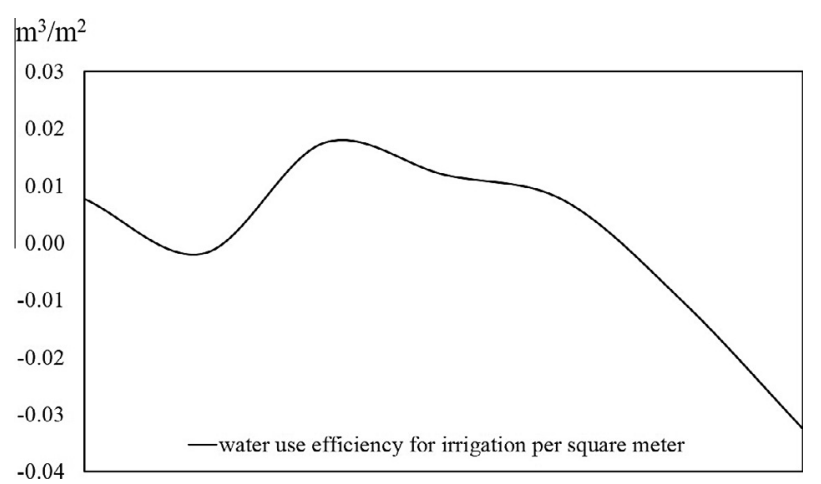

Fig. 8. Changes of water use for irrigation in per square meter in Gansu 2002-2008.

government invested on large water projects in Gansu for supplementing water supply and enhancing water facilities. Furthermore, advanced water-saving technology might contribute to enhancing efficiency of water use. For instance, the total water-saving irrigation area of Gansu was increasing from $7799.84 \mathrm{~km}^{2}$ in 2002 to $8206.17 \mathrm{~km}^{2}$ in 2008 . Water-saving area were continually expanding in Jiuquan City and Baiyin City in Fig. 7.

Efficiency of water use for irrigation also had been increasing since water use for irrigation in per square meter was decreased from $0.75 \mathrm{~m}^{3}$ in 2002 to $0.71 \mathrm{~m}^{3}$ in 2008 in Fig. 8. The distribution of efficiency changes of water use in administrative regions further illustrate water-saving area expansion had mitigated water scarcity in drought area, such as Jiuquan City and Baiyin City in Fig. 9.

Thus, we designed Scenario III that assume natural water supply decrease $5 \%$ with urbanization demand for economic output increase $10 \%$, and government investment of water-saving for 


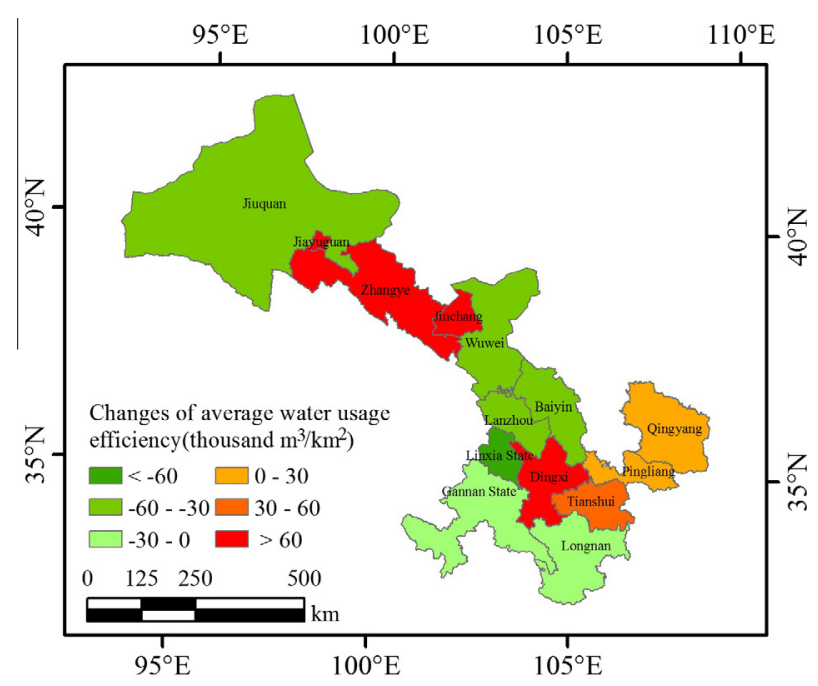

Fig. 9. Changes of water use efficiency by administrative regions in Gansu province 2002 vs 2008.

increasing water supply $1 \%$. The empirical results shows that firstly governmental financing (GOVENT) would be depreciated under Scenario II in Table 6. Furthermore, because the Scenario III is designed under the following future 5 years from 2007 to 2012. According to John W. Kendrick's empirical analysis findings in 1961, "the difference between the growth rate of output and the growth rate of input is equal to the difference between the growth rate of input prices and the growth rate of output prices," and based on the interpretation of "productivity gains are distributed to workers and investors by the market mechanism." Gross Domestic Products under Scenario III also loses in Model IIV because production factor returns lose in Table 9, but with a mitigation of possible loss if we assume without government investment on water projects. It makes sense that with the ratio of the factor input price in 2012-2007 was higher than the depreciated loss that is caused by government investment of water projects, which illustrates economic efficiency is getting improved by government investment but with a depreciation of present value of social welfare.

In a short summary of empirical results, Model IV gave a moderate construction to present interactions and interrelationships of the changes between water supply and water demand. Through three sequential scenarios based on water supply shock, urbanization demand shock, and possible water production due to government investment on water projects, it has been sequentially proved that relatively proportional changes of total outputs, exchange price units, household utilities and net nominal incomes, factor returns and total GDP were all caused by quantity changes of water scarcity. Therefore, when water supply is barely decreased

Table 9

Changes of Kendrick notes GDP and factor price in Gansu under Scenario III compare to changes of real national average price index from 2007 to 2012.

\begin{tabular}{llll}
\hline (\%) & \multicolumn{1}{l}{ Model } & $\begin{array}{l}\text { a National average } \\
\text { ratio }(1978=100)(\text { Year } \\
2009 / 2007-1) * 100 \%\end{array}$ & $\begin{array}{l}\text { a National average ratio } \\
(1978=100)(\text { Year 2012/ } \\
\end{array}$ \\
& & $2007-1) * 100 \%$ \\
\hline DPFC & -16.11 & -19.5 & -55.6 \\
WATER & -79.31 & 0.0 & -44.6 \\
LAND & -49.37 & -63.6 & -172.9 \\
LAB & 1.23 & -17.2 & -60.3 \\
CAP & -0.05 & -6.4 & -18.7
\end{tabular}

a Data from National Bureau of Statistics of the People's Republic of China website. because of microclimate changes, water demand is a driving force to systematically reshape the economic structure, and governmental investment on large water projects is not a perfect solution for improving current social welfare but enhancing economic efficiency of water use, eventually it will benefit future.

\subsection{Calibration and validation}

We used econometrical validation of CGE modeling frameworks to test changes of water use from the demand side. It proved that the actual changes might be severer than the moderate Model IV presenting. Because water price is controlled by Provincial Government, it is stable over time. Thereby to be represented, we used the urban and rural consumption price index. Nonparametric methods: Bootstrap Estimation gave analysis results of the price variability of statistics between subsamples of water use with respect to urban and rural price index by using software of STATA. Analysis results based on dataset of 2002-2008 showed water use for urban construction has a negative relationship with urban Consumption Price Index, and a positive relationship but lower than $0.3 \%$ changes with Producer Price Index. The validation results are presented in Appendix C Fig. 10. It demonstrated urban household purchase decreased $2.81 \%$ when water demand increased $1 \%$ for urbanization and environmental adaptation. Note that it is without water supply shock and urbanization demand shock, apparently, it is severer than the changes of Net Household Income under Scenario II. Therefore, the actual changes might be severer than the moderate Model IV presenting. Logically, the effect of government investment on water projects might contribute to mitigation of social welfare loss caused by water scarcity in arid Gansu more than it actually did.

\section{Conclusions and discussions}

In this study, improved Computable General Equilibrium (CGE) Model was designed by introducing natural capital, water and land, into the modeling framework. Water and land have been partially valued and plugged into Social Accounting Matrix (SAM) to indicate relative demands. Water use for urbanization and environmental adaptation as a part of water demand is mainly provided by water engineering and financed by Central Government and Provincial Government. It is outside of systematic balancing but have a huge impacts on economic structure and sustainable development in dry rural area. Study on total regional water demand has to consider a general equilibrium as an analysis tool to systematically explore interrelationships and interactions at a regional extent. Thereby, based on unit price assumption in Computable General Equilibrium (CGE) Model, economic valuation of water use provides a leverage through marketized mechanism to analyze interaction and interrelationships between water consumption and economic activities with governmental financing. Systematic analysis in laboratorial experiments are provided by GAMS (The General Algebraic Modeling System) to test relatively proportional changes in the modeling system under different scenarios. In this

Table 10

Indices of Percentage of Precipitation Anomalies (PPA) gradient at different drought level.

\begin{tabular}{lll}
\hline Gradient & Level & $\begin{array}{l}\text { Percentage of precipitation anomalies } \\
\text { Annually }\end{array}$ \\
\hline 1 & No drought & $-15<\mathrm{Pi}$ \\
2 & Slight drought & $-30<\mathrm{Pi} \leqslant-15$ \\
3 & Moderate drought & $-40<\mathrm{Pi} \leqslant-30$ \\
4 & Heavy drought & $-45<\mathrm{Pi} \leqslant-40$ \\
5 & Extreme drought & $\mathrm{Pi} \leqslant-45$ \\
\hline
\end{tabular}


. estat bootstrap,a11

Linear regression

Number of obs

Replications

$\begin{array}{lr}= & 75 \\ = & 1000\end{array}$

\begin{tabular}{|c|c|c|c|c|c|c|}
\hline 1n_mun & $\begin{array}{c}\text { observed } \\
\text { Coef. }\end{array}$ & Bias & $\begin{array}{l}\text { Bootstrap } \\
\text { Std. Err. }\end{array}$ & [95\% conf. & Interva1] & \\
\hline $0.1 n \_p m u n$ & 0 & 0 & 0 & $\begin{array}{l}0 \\
0\end{array}$ & $\begin{array}{l}0 \\
0\end{array}$ & (N) \\
\hline year & .02961997 & .0180118 & .60136244 & $\begin{array}{l}-1.149029 \\
-1.208742 \\
-1.347552\end{array}$ & $\begin{array}{l}1.208269 \\
1.135581 \\
1.033985\end{array}$ & $\begin{array}{l}\text { (BC) } \\
\text { (N) } \\
\text { (P) } \\
\text { (BC) }\end{array}$ \\
\hline 1n_urban & -2.8092506 & 2.224471 & 50.884353 & $\begin{array}{l}-102.5407 \\
-105.4398 \\
-115.9721\end{array}$ & $\begin{array}{l}96.92225 \\
92.99554 \\
89.78864\end{array}$ & $\begin{array}{l}\text { (N) } \\
\text { (P) } \\
\text { (BC) }\end{array}$ \\
\hline 1n_rural & 2.1907244 & -2.617082 & 60.509555 & $\begin{array}{r}-116.4058 \\
-109.8581 \\
-101.658\end{array}$ & $\begin{array}{l}120.7873 \\
128.4637 \\
159.7356\end{array}$ & $\begin{array}{l}\text { (N) } \\
\text { (P) } \\
\text { (BC) }\end{array}$ \\
\hline 1n_ppi & .27989865 & .3210444 & 8.7638266 & $\begin{array}{l}-16.89689 \\
-17.10091 \\
-18.56738\end{array}$ & $\begin{array}{l}17.45668 \\
16.72806 \\
15.51221\end{array}$ & $\begin{array}{l}\text { (N) } \\
\text { (P) } \\
\text { (BC) }\end{array}$ \\
\hline _cons & -58.517233 & -36.53797 & 1160.8324 & $\begin{array}{l}-2333.707 \\
-2180.092 \\
-1970.019\end{array}$ & $\begin{array}{l}2216.672 \\
2316.929 \\
2647.507\end{array}$ & $\begin{array}{l}\text { (N) } \\
\text { (P) } \\
\text { (BC) }\end{array}$ \\
\hline
\end{tabular}

(N) normal confidence interval

(P) percentile confidence interval

(BC) bias-corrected confidence interval

Fig. 10. Validation results of nonparametric methods: Bootstrap Estimation Results in STATA

paper, after explored regional hydro-economic modeling from both supply side and demand side, three-nested Constant Elasticity of Substitution (CES) production function was introduced to modeling four production factors which contribute to outputs of each sector from the demand side. Thereafter, semiparametric nested factor demand functions interpreted the demand of factor inputs at four level of economic scale in a short run.

Empirical results showed modeling frameworks were well-behaved to illustrate the following key findings. Based on sequentially designing three scenarios, firstly, sectoral outputs can decrease when water supply shocked by $5 \%$; although water scarcity was mitigated from 2002 to 2008 , water demands for urbanization and environmental adaptation broke down the equilibrium path when taking the ecological valuation into account. Secondly, huge governmental financing on water projects bring present value of social welfare depreciated. Water use for municipal environment adaptation will continually pressure water supply side. Water unit price can be sharply increased by water scarcity and increasing cost of factor inputs. Thirdly, increasing governmental financing on water production projects depreciate present value of social welfare but benefit future generation by enhancing economic efficiency of water use. Meanwhile, one of the key issues is to release some limitation of land properties in China. However, since the non-zero transaction cost of land mobility breaks through the assumption of perfectly-competitive marketized mechanism with zero transaction cost, increasing governmental financing on water production projects have expanded water-saving area from 2002 to 2008 in drought regions of Gansu Province. That can be considered as a compromised policy-oriented implementation of land use with water use.

Although the actual water-saving irrigation area might be slightly lower than the publish data records (Liu et al., 2008), this research proved that government investment on large water projects will enhance economic efficiency but depreciate present value of social welfare in order to benefit future generation in the study area. Gansu Provincial Water Resource Bureau had implemented a stimulating package to promoting "Water-Saving Society". Advanced techniques of agricultural irrigation for water-saving including spray irrigation, microperfusion pumping, low-pressure water transferring pipes, and anti-seepage of channels were popularized all over the Gansu Province. From 1999, Gansu was set as one of the most important provinces to implement the project of returning farmland to woodland or grassland. Until the end of 2007, there were about total $17454.21 \mathrm{~km}^{2}$ of cultivated land converted to forest or grassland. Water and soil conservation projects had covered $2025 \mathrm{~km}^{2}$ including eleven large projects for irrigation facilities and 323 of warp land dams, seventeen projects for water-efficient-facilities, twenty projects of potable water equipment for 209 thousand population in 76 counties. Total more than 510 million in 2005 USD were invested to large water projects; and 1587 Water User Associations were set up in Gansu Province (Provincial Water Resource Bureau, 2014; Chen et al., 2005). Therefore, water scarcity was mitigated from 2002 to 2008 partially due to government investment on water conservancy facilities, but reasoning of recycling improvement, environmental policy-based punishment, and resident aware of water retrenchment still have to be illustrated in further studies.

Some issues in modeling framework need to be further researched as well. In this study, Model IV, when setting all factor are mobile, is a moderate construction to present interactions and interrelationships of the changes of water allocation. After four models were tested by setting four production factors with different mobility conditions, nonparametric validation analysis with comparing analysis proved Model IV is well-behaved. However, the empirical analysis show that water policy package with huge governmental financing would break down the equilibrium path. Because urbanization expansion with environmental adaptation will highly depend on water supply, traditional government-control water price might not effectively impact on water demand and water supply. Moreover, limitation of land property mobility may also pressure systematical management of water resource through both ecologic and economic system. Hence, stimulating alternatives of water production and water-saving promotion will attribute to further study on economic efficiency of water productivity in a more complex system.

\section{Conflicts of interest}

The authors declare no conflict of interest. 


\section{Author contributions}

All authors read and approved the final manuscript.

\section{Acknowledgments}

This research was financially supported by the major research plan of the National Natural Science Foundation of China (Grant No. 91325302) and the National Natural Science Funds of China for Distinguished Young Scholar (Grant No. 71225005). The authors would like to thank Qian Zhang and Zhihui Li from the Chinese Academy of Sciences, Feng Wu and Zhongxiao Sun from Beijing Normal University, Yongwei Yuan and Gui Jin from Hubei University for their contributions on revised suggestions and data clearing in this paper.

\section{Appendix A. Deductive reasonings of Stone-Geary utility function and consumption theory}

Apply for indirect utility function form:

$$
\begin{aligned}
& \text { if }: e(p, u)=\sum_{j} P_{i} x_{i}^{h}=y \\
& \Rightarrow v(p, y)=\left(y-\sum_{j} P_{i} \mu_{i}\right) \prod\left(\frac{\beta_{j}}{P_{j}}\right)^{\beta_{j}}
\end{aligned}
$$

Using Roy's Identity: $x_{i}^{h}(p, y)=-\frac{\partial v(p, y)}{\partial p_{i}} / \frac{\partial v(p, y)}{\partial y}$.

Would also get:

$$
\begin{aligned}
& \frac{\partial v(p, y)}{\partial y}=\prod\left(\frac{\beta_{j}}{P_{j}}\right)^{\beta_{j}} \\
& \frac{\partial v(p, y)}{\partial p_{i}}=\left(-\left(\frac{\beta_{j}}{P_{j}}\right) y-\mu_{i}+\left(\frac{\beta_{j}}{P_{j}}\right)\left(\sum_{j} P_{i} \mu_{i}\right)\right) \prod\left(\frac{\beta_{j}}{P_{j}}\right)^{\beta_{j}} \\
& \Rightarrow X_{i}=\mu_{i}+\frac{\beta_{j}}{P_{i}}\left(y-\sum_{j} P_{j} \mu_{j}\right)
\end{aligned}
$$

\section{Appendix B. Calculation of percentage of precipitation anomalies}

$$
P_{i}=\frac{P-\bar{P}}{\bar{P}} \times 100 \%
$$

where $P$ is the precipitation in time $i$, unit: $\mathrm{mm}$.

where $\bar{P}$ is the average precipitation in time $i$ caculated by the following formula, unit: $\mathrm{mm}$.

$\bar{P}=\frac{1}{n} \sum_{i=1}^{n} P_{i}$

where $n$ is from 1 to 30 year, $i=1,2, \ldots, n$.

According to the following table, each pixel unit of region will be categorized into the corresponding level of drought. This method is appropriate to semi-arid or subhumid zone. See Table 10.

\section{Appendix C. Validation results of nonparametric methods}

Bootstrap Estimation Results in STATA as shows in the following Fig. 10

\section{References}

Arrow, K.J., 1969. The organization of economic activity: issues pertinent to the choice of market versus nonmarket allocation. Anal. Eval. Public Expenditure: PPB Syst. 1, 59-73.
Blignaut, J., Van Heerden, J., 2009. The impact of water scarcity on economic development initiatives. Water SA 35 (4), 415-420.

Carson, R.T., Hanemann, W.M., Wegge, T.C., 2009. A nested logit model of recreational fishing demand in Alaska. Mar. Res. Econ. 24 (2), 101-129.

Chen, Y., Zhang, D., Sun, Y., Liu, X., Wang, N., Savenije, H.H., 2005. Water demand management: a case study of the Heihe River Basin in China. Phys. Chem. Earth, Parts A/B/C 30 (6), 408-419.

Christian-Smith, J., Gleick, P.H., Cooley, H., 2011. US water policy reform. In: The World's Water. Island Press/Center for Resource Economics, pp. 143-155.

Ciscar, J.C., Iglesias, A., Feyen, L., Szabó, L., Van Regemorter, D., Amelung, B., Soria, A., 2011. Physical and economic consequences of climate change in Europe. Proc. Natl. Acad. Sci. 108 (7), 2678-2683.

Coase, R.H., 1960. Problem of social cost, the. JL \& Econ. 3, 1.

Collins, J.P., Kinzzig, A., Grimm, N.B., Fagan, W.F., Hope, D., Wu, J., Borer, E.T., 2000. A New Urban Ecology Modeling human communities as integral parts of ecosystems poses special problems for the development and testing of ecological theory. Am. Sci. 88 (5), 416-425.

Colombo, S., Hanley, N., Louviere, J., 2009. Modeling preference heterogeneity in stated choice data: an analysis for public goods generated by agriculture. Agric. Econ. 40 (3), 307-322.

Dawkins, C., Srinivasan, T.N., Whalley, J., 2001. Calibration. Handbook of Econometrics, vol. 5, pp. 3653-3703.

Deng, X. Jiang, Q.O., Zhan, J., He, S., Lin, Y., 2010. Simulation on the dynamics of forest area changes in Northeast China. J. Geog. Sci. 20 (4), 495-509.

Deng, X., Yin, F., Lin, Y., Jin, Q., Qu, R., 2012. Equilibrium analyses on structural changes of land uses in Jiangxi Province. J. Food Agric. Environ. 10 (1), 846852

Deng, X., Zhang, F., Wang, Z., Li, X., Zhang, T., 2014. An extended input output table compiled for analyzing water demand and consumption at county level in China. Sustainability 6 (6), 3301-3320.

Diao, X., Dinar, A., Roe, T., Tsur, Y., 2008. A general equilibrium analysis of conjunctive ground and surface water use with an application to Morocco. Agric. Econ. 38 (2), 117-135.

Dudu, H., Chumi, S., 2008. Economics of irrigation water management: a literature survey with focus on partial and general equilibrium models. World Bank Policy Research Working Paper Series, Vol.

Egan, K.J., Herriges, J.A., Kling, C.L., Downing, J.A., 2009. Valuing water quality as a function of water quality measures. Am. J. Agric. Econ. 91 (1), 106-123.

Griffith, M., 2012. Water resources modeling: a review. In: Economic Modeling of Water. Springer, Netherlands, pp. 59-77.

Harris, T.R., Mapp Jr., H.P., 1980. A control theory approach to optimal irrigation. Southern J. Agric. Econ.

Harris, T.R., Mapp, H.P., 1986. A stochastic dominance comparison of waterconserving irrigation strategies. Am. J. Agric. Econ. 68 (2), 298-305.

Jørgensen, Sven Erik, 1996. Integration of Ecosystem Theories: A Pattern. Kluwer, Dordrecht.

Koesler, S., Schymura, M., 2012. Substitution elasticities in a CES production framework. An empirical analysis on the basis of non-linear least squares estimations. An Empirical Analysis on the Basis of Non-Linear Least Squares Estimations, 11-007.

Lemke, C.E., Howson Jr., J.T., 1964. Equilibrium points of bimatrix games. J. Soc. Ind. Appl. Math. 12 (2), 413-423.

Lioubimtseva, E., Cole, R., Adams, J.M., Kapustin, G., 2005. Impacts of climate and land-cover changes in arid lands of Central Asia. J. Arid Environ. 62 (2), 285308

Liu, Y., Huang, J.K., Wang, J.X., Rozelle, S., 2008. Determinants of agricultural water saving technology adoption: an empirica 1 study of 10 provinces of China. Ecol. Econ. 4 (4), 462-472.

McFadden, D., 1963. Constant elasticity of substitution production functions. Rev. Econ. Studies, 73-83.

Moss, T., 2004. The governance of land use in river basins: prospects for overcoming problems of institutional interplay with the EU Water Framework Directive. Land Use Policy 21 (1), 85-94.

Müller, F., Lenz, R., 2006. Ecological indicators: theoretical fundamentals of consistent applications in environmental management. Ecol. Ind. 6, 1-5.

Neary, J.P., 1997. RC Geary's Contributions to Economic Theory. Department of Economics, University College Dublin.

Grossmann, M. Dietrich, O, 2012. Integrated economic-hydrologic assessment of water management options for regulated wetlands under conditions of climate change: a case study from the Spreewald (Germany). Water Resour. Manage 26 (7), 2081-2108

Patten, B.C., 1995. Network integration of ecological extremal principles: exergy, energy, power, ascendancy, and indirect effects. Ecol. Model. 79, 75-84.

Pendakur, K., Sperlich, S., 2010. Semiparametric estimation of consumer demand systems in real expenditure. J. Appl. Econ. 25 (3), 420-457.

Pianosi, F., Ravazzani, G., 2010. Assessing rainfall-runoff models for the management of Lake Verbano. Hydrol. Process. 24 (22), 3195-3205.

Gansu Provincial Water Resource Bureau, 2014. Gansu Bulletin of Soil and Water Conservation 2012, Gansu Provincial Water Resource Bureau.

Rosegrant, M.W., Ringler, C., McKinney, D.C., Cai, X., Keller, A., Donoso, G., 2000. Integrated economic-hydrologic water modeling at the basin scale: the Maipo River basin. Agric. Econ. 24 (1), 33-46.

Sato, K., 1967. A two-level constant-elasticity-of-substitution production function. Rev. Econ. Stud. 34 (2).

Seto, K.C., Kaufmann, R.K., Woodcock, C.E., 2000. Landsat reveals China's farmland reserves, but they're vanishing fast. Nature 406 (6792), 121-121. 
Seung, C.K., Englin, J.E., Harris, T.R., 1997. Application of computable general equilibrium model to derive impacts of surface water reallocation policy. In: Western Agricultural Economics Association 1997 Annual Meeting July, pp. 13-16.

Seung, C., Harris, T., Narayanan, R., 1998. A computable general equilibrium approach to surface water reallocation policy in rural Nevada. In: 1998 American Agricultural Economics Association Meeting.

Seung, C.K., Harris, T.R., Englin, J.E., Netusil, N.R., 1999. Application of a computable general equilibrium (CGE) model to evaluate surface water reallocation policies. Rev. Reg. Stud. 29 (2), 139-155.

Shen, K., Whalley, J., 2013. Capital-Labor-Energy Substitution in Nested CES Production Functions for China. National Bureau of Economic Research.

Shi, M., Tao, W., Zhao, X., 2010. A GIS-based bio-economic model applied in water resource management in Shiyang River Basin, Gansu Province, China. In: Sustainability in Food and Water. Springer, Netherlands, pp. 61-71.

Singh, R.B., Grover, A., Zhan, J., 2014. Inter-seasonal variations of surface temperature in the urbanized environment of Delhi using landsat thermal data. Energies 7 (3), 1811-1828.

Sivakumar, B., 2011. Global climate change and its impacts on water resources planning and management: assessment and challenges. Stoch. Environ. Res. Risk Assess. 25 (4), 583-600.

Smyth, Russell, Narayan, Paresh Kumar, Shi, Hongliang, 2011. Substitution between energy and classical factor inputs in the Chinese steel sector. Appl. Energy 88 (1), 361-367.

Stroup, L.J., 2011. Adaptation of US water management to climate and environmental change. Prof. Geogr. 63 (4), 414-428.
Su, Xuanming, Zhou, Weisheng, Nakagami, Ken'Ichi, Ren, Hongbo, Mu, Hailin, 2012. Capital stock-labor-energy substitution and production efficiency study for China. Energy Econ. 34 (4), 1208-1213.

Tekken, V., Kropp, J.P., 2012. Climate-driven or human-induced: indicating severe water scarcity in the Moulouya River Basin (Morocco). Water 4 (4), 959-982.

Tirado, D., Lozano, J., Gomez Gomez, C.M., 2010. Economic regional impacts of water transfers: the role of factor mobility in a case study of the agricultural sector in the Balearic Islands. Economía agraria y recursos naturales 10 (2).

van Heerden, J.H., Blignaut, J., Horridge, M., 2008. Integrated water and economic modelling of the impacts of water market instruments on the South African economy. Ecol. Econ. 66 (1), 105-116.

Veldkamp, A., Verburg, P.H., 2004. Modelling land use change and environmental impact. J. Environ. Manage. 72 (1-2), 1-3.

Wang, R.S., Li, F., Hu, D., Li, B.L., 2011. Understanding eco-complexity: socialeconomic-natural complex ecosystem approach. Ecol. Complexity 8 (1), 15-29.

Wang, S.L., Liu, X.D., Wang, J.H., Li, X.B., Jin, M., Zhang, X.L., 2012. Evaluation on forest ecosystem services value in Gansu province. J. Arid Land Res. Environ. 26 (3), 139-145.

Water Resources of the People's Republic of China, 2003-2009. Year Book of Ministry of Water Resources of the People's Republic of China 2002-2008, Water Resources of the People's Republic of China.

Watson, Philip S., Davies, Stephen, 2011. Modeling the effects of population growth on water resources: a CGE analysis of the South Platte River Basin in Colorado. Ann. Reg. Sci. 46 (2), 331-348. 